\title{
107 yaş, hepatobilier cerrahi ve torakal epidural anestezi: başarılı bir deneyim
}

\author{
Age 107, hepatobiliary surgery and thoracic epidural anesthesia: a successful \\ experience
}

Gülçin Aydın, Oktay Aydın, Faruk Pehlivanlı

Gönderilme tarihi:30.03.2018

Kabul tarihi:08.06.2018

Özet

Üst abdominal cerrahide kronik obstrüktif akciğer hastalığı (KOAH)'lı hastaların anestezi yönetimi oldukça zordur. Genel anestezi uygulaması postoperatif pulmoner ve kardiyak komplikasyonları da beraberinde getirmektedir. Biz bu yazımızda genel anesteziye iyi bir alternatif amacıyla Evre 4 KOAH geriatrik hastada sedasyon eşliğinde torakal epidural anestezi deneyimimizi paylaşmayı amaçladık.

Anahtar kelimeler: Üst abdominal cerrahi, epidural anestezi.

Aydın G, Aydın O, Pehlivanlı F. 107 yaş, hepatobilier cerrahi ve torakal epidural anestezi: başarılı bir deneyim. Pam Tıp Derg 2019;12:167-168.

\begin{abstract}
The anesthesia management of chronic obstructive pulmonary disease (COPD) patients in upper abdominal surgery is fairly difficult. The application of general anesthesia includes post-operative pulmonary and cardiac complications. We aim to share our experience of a good alternative to general anesthesia in a stage four COPD geriatric patient with thoracic epidural block.
\end{abstract}

Keywords: Upper abdominal surgery, epidural anesthesia.

Aydın G, Aydın O, Pehlivanlı F. Age 107, hepatobiliary surgery and thoracic epidural anesthesia: a successful experience. Pam Med J 2019;12:167-168.

\section{Giriş}

Komorbiditesi olan geriatrik hastalarda perioperatif pulmoner komplikasyonlar oldukça yaygındır. Özellikle kronik obstrüktif akciğer hastalığı (KOAH) olanlarda postoperatif pulmoner komplikasyon açısından risk \%300700 daha yüksektir. Üst abdominal cerrahilerde solunum kas güçsüzlüğü, azalmış öksürük refleksi ve karın ağrısı, akciğer hacimlerinde azalmaya ve atelektaziye yol açmaktadır [1, 2]. Biz bu olgu sunumu ile üst abdominal cerrahi geçiren 107 yaşındaki hastada sedasyon eşliğinde torakal epidural anestezi deneyimimizi literatür eşliğinde paylaşmayı amaçladık.

\section{Olgu Sunumu}

Kronik atrial fibrilasyonu ve evre 4 KOAH'ı olan 107 yaşında 60 kg erkek hasta Amerikan Anestezistler Derneği (ASA) IV risk grubunda değerlendirildi. Kolesistektomi ve koledokoduodenostomi planlanan hasta premedikasyon yapılmadan operasyon odasına alındı. Oksijen Saturasyonu $\left(\mathrm{SPO}_{2}\right)$ : \%85 olması üzerine maske ile 4 L/dk oksijen verildi. Sol radial arter kanülasyonu sonrası arteryal monitorizasyon ile beraber elektrokardiyografi (EKG) ve $\mathrm{SPO}_{2}$ monitörizasyonu uygulandı. Oturur pozisyona alınan hastada, $18 \mathrm{G}$ Touhy iğnesi ile T9-10 aralığından direnç kaybı yöntemiyle epidural aralığa ulaşıldı. $3 \mathrm{~mL} \% 2$ 'lik prilokain (Citanest ${ }^{\circledR} \% 2$, Astra Zeneca, Ankara, Türkiye) ile test dozu uygulandi. Epidural

Gülçin Aydın, Dr.Öğr.Üyesi, Kırıkkale Üniversitesi Tıp Fakültesi Hastanesi, Anesteziyoloji ve Reanimasyon AD. Yahşihan, KIRIKKALE, e-posta:drgulcinaydin@yahoo.com (orcid.org/0000-0001-9672-7666) (Sorumlu yazar)

Oktay Aydın, Dr.Öğr.Üyesi, Kırıkkale Üniversitesi Tıp Fakültesi Hastanesi, Genel Cerrahi AD. KIRIKKALE, e-posta:droktayaydin@gmail.com (orcid. org/0000-0001-5728-0128)

Faruk Pehlivanlı, Dr.Öğr.Üyesi, Kırıkkale Üniversitesi Tıp Fakültesi Hastanesi, Genel Cerrahi AD. KIRIKKALE, e-posta:drfapeh@hotmail.com (orcid. org/0000-0002-2175-8756) 
aralık teyyid edildikten sonra kateterizasyon uygulandı. Epidural kateter ucu $4 \mathrm{~cm}$ sefale doğru ilerletildi ve takiben $8 \mathrm{ml} \% 0,5^{\prime}$ lik bupivakain hidroklorür (Marcaine ${ }^{\circledR} \% 0,5$, Astra Zeneca, Ankara, Türkiye) ve $50 \mu \mathrm{g}$ fentanil (Fentany ${ }^{\circledR} \quad 0,05 \mathrm{mg} / \mathrm{ml}$ Johnson \& Johnson, Ankara, Türkiye) karışımı verildi. 15. dakikada yapılan pinprick testinde T4-T12 segmentleri arasinda yeterli sensoryal blok elde edildi. Bromage skoru bir idi. Cerrahi insizyonla beraber $4 \mathrm{mg} / \mathrm{kg} / \mathrm{saat}$ propofol (Propofol ${ }^{\circledR} \% 1$, Fresenius, Ankara, Türkiye) infüzyonu başlandı. Operasyon boyunca maske ile 4 L/dk oksijen verildi. Nazogastrik sonda uygulaması yapıldı. Epidural anesteziden yaklasik 20 dakika sonra hastanin kalp hizi 42/dk'ya düstü ve $0,5 \mathrm{mg}$ intravenöz atropin uygulaması ile kısa sürede normale döndü. Operasyonun 1. saatinde epidural kateterden $4 \mathrm{~mL} \% 0,5$ 'lik bupivakain hidroklorür ek doz uygulandı. Operasyon $75 \mathrm{dk}$ sürdü. Intraoperatif herhangi bir komplikasyon yaşanmadı. Postoperatif 24 saat yoğun bakımda takip edildi. Postoperatif 5 . saatte ağrısı için kateterden $4 \mathrm{~mL} \% 0,5$ 'lik bupivakain hidroklorür ve $50 \mu \mathrm{g}$ fentanil yapıldı. 24 saat sonra epidural kateter çekildi.

\section{Tartışma}

Üst abdominal cerrahide KOAH'lı hastaların anestezik yönetimi anestezistler için oldukça zordur. Genel anestezi uygulaması ciddi pulmoner komplikasyonları beraberinde getirmekle beraber [3] KOAH'lı geriatrik hastalarda yapılan TEA ile hem intraoperatif hem de postoperatif dönemde kardiyak ve respiratuar komplikasyonlar azalır. Bu prosedürün hastalar tarafından iyi tolere edildiği ve postoperatif dönemde de hastaların iyileşmesine de önemli ölçüde katkıda bulunduğu gösterilmiştir [4]. Özellikle postoperatif dönemde sağlanan epidural analjezi ile de kardiyak morbidite azalmakta, ağrı kontrolü ile atelektaziler önlenerek akciğer kapasitesinde iyileşme sağlanmakta, respiratuar fonksiyonlar ve kan oksijenasyonu da düzelmektedir [5]. Nitekim 107 yaşında evre IV KOAH hastamızda bu komplikasyonlar göz önünde tutularak genel anesteziye alternatif; sedasyon eşliğinde TEA tercih edildi. İntraoperatif ve postoperatif hiçbir komplikasyon yaşanmadı.

Sonuç olarak; üst abdominal cerrahi geçirecek KOAH'lı geriatrik hastalarda TEA'nin iyi bir tercih olabileceğini düşünmekteyiz.
Çıkar İlişkisi: Yazarlar çıkar ilişkisi olmadığını beyan eder.

\section{Kaynaklar}

1. Van Lier F, Van der Geest PJ, Hoeks SE, Van Gestel YR, $\mathrm{Hol}$ JW, Sin DD. Epidural analgesia is associated with improved health outcomes of surgical patients with chronic obstructive pulmonary disease. Anaesthesiol 2011;115:315-321.

2. Consani G, Amorese G, Boggi U, Comite C, Avagliano E. Laparotomic sub-total gastrectomy under awake thoracic epidural anaesthesia: a successful experience. Updates Surg 2013;65:255-256.

3. Gonzalez Mendibil I, Postigo-Morales S, GonzalezLarrabe I, Arizaga-Maguregi A. Thoracic epidural anesthesia for open cholecystectomy in severe lung disease. Description of a case and review of the literatüre. Rev Esp Anestesiol Reanim 2015;62:576579.

4. Abd Elrazek E, Thornton M, Lannigan A. Effective awake thoracic epidural anesthetic for major abdominal surgery in two high-risk patients with severe pulmonary disease-a case report. Middle East J Anaesthesiol 2010;20:891-895.

5. Pöpping DM, Elia N, Marret E, Remy C, Tramèr MR. Protective effects of epidural analgesia on pulmonary complications after abdominal and thoracic surgery: a meta-analysis. Arch Surg 2008;143:990-999. 